\title{
VARIASI PERUBAHAN PENGGUNAAN LAHAN PADA BERBAGAI TIPE BENTUKLAHAN DAN KAITANNYA DENGAN ALIRAN DASAR SUNGAI PADA DAS KEDUANG PROVINSI JAWA TENGAH (The Variation of Land-Use Change in Various Landform Type and Its Correlation With River Baseflow on The Keduang Watershed in Central Java Province)
}

\author{
Bokiraiya Latuamury ${ }^{*}$, Sudarmadji² dan Slamet Suprayogi ${ }^{2}$ \\ ${ }^{1}$ Jurusan Kehutanan, Fakultas Pertanian, Universitas Pattimura, \\ Jl. Ir. M. Putuhena, Poka, Ambon 97123. \\ ${ }^{2}$ Jurusan Geografi Lingkungan, Fakultas Geografi, Universitas Gadjah Mada, \\ Sekip Utara, Yogyakarta 55281.
}

*Penulis korespondensi. Tel: 081227399997. Email: okky.environmentalscience@ gmail.com.

Diterima: 8 Desember 2015

Disetujui: 24 Februari 2016

\begin{abstract}
Abstrak
Penelitian variasi penggunaan lahan dan kaitannya dengan aliran dasar skala DAS semakin banyak digunakan, sebagai akibat dari kebutuhan air yang terus meningkat. Karakteristik DAS mempengaruhi proses perubahan curah hujan sebagai masukan, dan aliran sungai sebagai keluaran. Untuk itu penting dilakukan penelitian dengan tujuan untuk menganalisis secara geospasial mengenai variasi perubahan penggunaan lahan pada berbagai tipe bentuklahan dalam kaitannya dengan aliran dasar sungai. Hasil analisis statistik variasi penggunaan lahan pada berbagai tipe bentuklahan dalam kaitannya dengan aliran dasar sungai secara geospasial menunjukkan bahwa ada perubahan yang signifikan. Karakteristik aliran dasar sungai di DAS Keduang Kabupaten Wonogiri Provinsi Jawa Tengah menunjukkan bentuk kurva resesi landai dengan koefisien resesi 0,99 dan volume aliran dasar rata-rata cukup tinggi. Analisis kurva resesi menggambarkan kondisi aliran dasar memiliki kemampuan menyimpan dan meloloskan aliran optimal. Dengan demikian pengelolaan ekosistem sungai secara bersinergi dan berkelanjutan dapat mempertahankan pola pemanfaatan sungai oleh masyarakat sekitar sebagai sebuah alternatif ketersediaan air masyarakat lokal.
\end{abstract}

Kata kunci: aliran dasar sungai, bentuklahan, ekosistem sungai, kurva resesi, penggunaan lahan.

\begin{abstract}
Nowadays, research that concerning in the relation between land use change and baseflow in watershed scale are increased due to the increasing water demand. Watershed characteristic typically affecting the alteration of rainfall as input and river flow as output. Therefore, this research aims to perform geospatial analysis on the variation of landuse change in various landform type and its correlation with river baseflow. Results from statistical analysis of landuse on the various types of landform and its correlation with river baseflow indicated that there are significant changes. Baseflow characteristic in Keduang watershed, Wonogiri, Central Java Province shows that the shape of recession curve is ramps with coefficient 0,99 and high baseflow average. Recession curve analysis describes that baseflow condition capable in storing and through the optimum flow. Hence, synergic and sustainable river ecosystem management could maintain river utilization pattern by the local community as an alternative for local water supply.
\end{abstract}

Keywords: river baseflow, landform, landuse, river ecosystem, recession curve.

\section{PENDAHULUAN}

Persoalan sumberdaya air berkaitan dengan waktu dan distribusi debit aliran (Asdak, 2002). Ekosistem sungai berubah drastis dengan terganggunya keseimbangan daya dukung sumberdaya air pada berbagai morfologi bentanglahan sehingga menimbulkan lahan-lahan kritis, dan mengganggu kemampuan lahan meresapkan, menyimpan dan meloloskan air kedalam tanah (Yu-Pin dkk., 2007). Penyebab utama gangguan pada ekosistem DAS adalah manusia dan bencana alam. Sistem hidrologis yang terganggu, di mana menyebabkan melimpahnya air di musim hujan dan kekurangan air di musim kemarau. Kondisi yang sama juga menyebabkan perbedaan yang tajam antara debit sungai musim hujan dan musim kemarau sebagai indikator rusaknya ekosistem DAS (Turner dkk., 2001).

DAS Keduang merupakan DAS skala besar dengan luas $\pm 387 \mathrm{~km}^{2}$, dengan panjang sungai utama 36,848 km; kerapatan drainase (drainage 
density ) 2,999 km/ $\mathrm{km}^{2}$ tergolong pengatusan baik, dengan nilai $1<D d<5$. Nilai Dd DAS Keduang memiliki kerentanan terhadap banjir kategori sedang. Kategori nilai Dd tinggi sifat impermeabel dan rentan terhadap banjir dan erosi, sedangkan Dd rendah permeabel dengan infiltrasi rendah, namun kerentanan terhadap banjir rendah. Nilai rasio sirkularitas (Circulation Ration, Rc) 0,580 tergolong antara $0,34<\mathrm{Rc}<0,66$ menunjukkan bahwa bentuk DAS Keduang adalah elips, yakni debit puncak Qp sedang, rising time (Tp) lambat, dan $\mathrm{Tc}$ dengan waktu resesi lebih lambat. Kategori nisbah percabangan sungai (Bifurcation Ratio- $\mathrm{Rb}$ ) 0,998 yakni termasuk $\mathrm{Rb}$ tinggi $<1$, termasuk kriteria normal dengan puncak banjir dan resesi sedang. Menurut Seyhan (1990) bahwa Rb Tinggi jika Rb < 1, memiliki erosi dipercepat, infiltrasi rendah dan mendukung banjir; sedangkan $\mathrm{Rb}$ rendah, jika $\mathrm{Rb}>1$ memiliki airtanah dalam, infiltrasi besar dan surface runoff kecil (Wittenberg dan Sivapalan, 1999).

Karakteristik hidrologi suatu daerah sangat dipengaruhi oleh morfometri DAS dan geomorfologi terutama bentuklahan, dalam kaitannya dengan responnya terhadap aliran dasar sungai. Oleh karena itu, penelitian ini bertujuan untuk menganalisis secara geospasial mengenai variasi perubahan penggunaan lahan pada berbagai tipe bentuklahan dalam kaitannya dengan aliran dasar sungai.

\section{METODE PENELITIAN}

\section{Waktu dan Lokasi}

Penelitian ini dilaksanakan di DAS Keduang Kabupaten Wonogiri Provinsi Jawa Tengah selama sebulan mulai dari 10 Januari - 11 Februari 2013. DAS ini dipertimbangkan untuk diteliti karena memiliki data SPAS (Stasiun Pengamat Aliran Sungai) debit kisaran jam, yang layak digunakan untuk analisis karakteristik resesi aliran dasar, dengan variasi penggunaan lahan yang dinamis.

\section{Prosedur Penelitian}

Penelitian ini mencakup dua bagian, yakni melakukan analisis citra satelit untuk memetakan variasi penggunaan lahan pada berbagai unit bentuklahan, dan mengumpulkan data debit untuk melakukan pemisahan aliran menjadi aliran dasar. Hasil pemisahan aliran dasar kemudian menganalisis kurva resesi untuk karakteristik resesi aliran dasar. Analisis statistik spasial digunakan untuk mengetahui keterkaitan variasi penggunaan lahan pada berbagai unit bentuklahan terhadap karakteristik resesi aliran dasar.

\section{Variasi Penggunaan Lahan}

Variasi perubahan penggunaan lahan terjadi secara cepat dapat dilakukan dengan memanfaatkan aplikasi teknologi penginderaan jauh dan sistem informasi geografi untuk memperoleh data multispasial dan multitemporal dari citra satelit yang runut waktu. Penggunaan citra satelit dilakukan untuk mendelineasi penggunaan lahan secara cepat dan akurat dalam periode waktu yang teratur (Pontius dan Schneider, 2001). Peta perubahan penggunaan lahan diperoleh dari analisis citra satelit landsat $\mathrm{ETM}^{+}$dengan periode waktu tahun 2000 2010.

Penggunaan lahan di DAS Keduang didominasi oleh 6 kelas utama yakni hutan, lahan pertanian, pemukiman, semak/belukar, lahan kosong, dan tubuh air (Tabel 1), dengan 7 variasi perubahan penggunaan lahan yaitu hutan tetap menjadi hutan $(\mathrm{H}-\mathrm{H})$, perubahan hutan menjadi lahan pertanian $(\mathrm{H}-$ LP) dan hutan menjadi pemukiman (H-PMK), lahan pertanian tetap menjadi lahan pertanian (LP-LP), perubahan lahan pertanian menjadi hutan (LP-H), perubahan lahan pertanian menjadi pemukiman (LPPMK), dan pemukiman tetap menjadi pemukiman (PMK-PMK).

Variabel terikat dalam penelitian ini adalah aliran dasar, sedangkan variabel bebas meliputi variasi penggunaan lahan pada berbagai unit bentuklahan. Variabel tersebut terdiri atas $\left(X_{1}\right)=$ variasi penggunaan lahan pada bentuklahan kerucut vulkan, $\left(\mathrm{X}_{2}\right)=$ variasi penggunaan lahan pada bentuklahan lereng atas gunungapi, $\left(\mathrm{X}_{3}\right)=$ variasi penggunaan lahan pada bentuklahan lereng tengah gunungapi, $\left(\mathrm{X}_{4}\right)=$ variasi penggunaan lahan pada bentuklahan lereng bawah gunungapi, $\left(\mathrm{X}_{5}\right)=$ variasi

Tabel 1. Kelas penggunaan lahan periode 2000 - 2010 yang dominan di DAS Keduang, Wonogiri, Jawa Tengah

\begin{tabular}{lrrr}
\hline \multirow{2}{*}{ Kelas penggunaan lahan } & \multicolumn{3}{c}{ Luas (Ha) } \\
\cline { 2 - 4 } & \multicolumn{1}{c}{2000} & \multicolumn{1}{c}{ Selisih } \\
\hline Hutan & 20939,17 & 9787,47 & $-11151,70$ \\
Lahan pertanian & 12778,33 & 11766,14 & $-1012,19$ \\
Pemukiman & 4793,93 & 16958,98 & 12165,06 \\
Semak/belukar & 28,35 & 28,35 & 0,00 \\
Lahan kosong & 61,78 & 61,78 & 0,00 \\
Tubuh air & 0,00 & 0,00 & 0,00 \\
\hline
\end{tabular}

Sumber : Analisis Citra Landsat 2000 dan 2010 (Anonim, 2010). 
penggunaan lahan pada bentuklahan escarpment, $\left(\mathrm{X}_{6}\right)=$ variasi penggunaan lahan pada bentuklahan lereng bawah perbukitan struktural, dan $\left(\mathrm{X}_{7}\right)=$ variasi penggunaan lahan pada bentuklahan perbukitan struktural. Variasi penggunaan lahan pada berbagai unit bentuklahan ini memberikan pengaruh yang berbeda terhadap aliran dasar sungai melalui analisis statistik secara parsial dan secara simultan (uji ANOVA).

\section{Analisis karakteristik resesi baseflow}

Hidrograf aliran pada bagian kurva resesinya terdiri dari beberapa komponen aliran yang berasal dari media yang berbeda, sehingga sifat pelepasan alirannya tidak sama. Perbedaan pelepasan air memungkinkan untuk melakukan pemisahan komponen aliran dari masing-masing sumber melalui pemisahan hidrograf aliran (Eckhardt, 2005).

Metode pemisahan aliran dasar dapat dilakukan dengan dua cara, yaitu fokus pada penentuan titik, di mana aliran dasar berpotongan (intersect) dengan sisi naik dan turun dari suatu hidrograf, dan metode filtering yang memproses data hidrograf aliran untuk memperoleh hidrograf aliran dasar.

Pendekatan grafis untuk pemisahan aliran dasar yang terdiri atas 3 metode (Nathan dan McMahon, 1990), yaitu :

1. The konstanta discharge method yang mempunyai asumsi bahwa aliran dasar bersifat konstan selama kejadian banjir. Nilai limpasan minimum sebelum sisi naik (rising limb) merupakan nilai konstan tersebut;

2. The konstanta slope method yang menghubungkan nilai awal dari sisi naik dengan titik belok (inflection point) pada sisi turun (receeding limb);

3. The concave method yang menggambarkan awal resesi aliran dimulai pada sisi turun dengan memproyeksikan hidrograf menurun (declining hydrographic) ke garis perpotongan dengan garis puncak hidrograf (crest). Garis perpotongan tersebut selanjutnya dihubungkan dengan titik belok pada sisi resesi.

Asumsi yang kedua, menyatakan bahwa hidrograf aliran dasar cenderung mengikuti pola hidrograf limpasan yang menggambarkan respon dari hujan. Metode yang dapat digunakan untuk menggambarkan asumsi kedua adalah metode filter digital (digital filter method), yang menggambarkan analisis dan pemrosesan data untuk memisahkan aliran tinggi dan aliran rendah, khususnya untuk pemisahan aliran dasar adalah :

$b_{t}=\alpha \cdot q_{t-1}+\frac{(1+\alpha)}{2} x\left(Q_{t}-Q_{t-1}\right)$

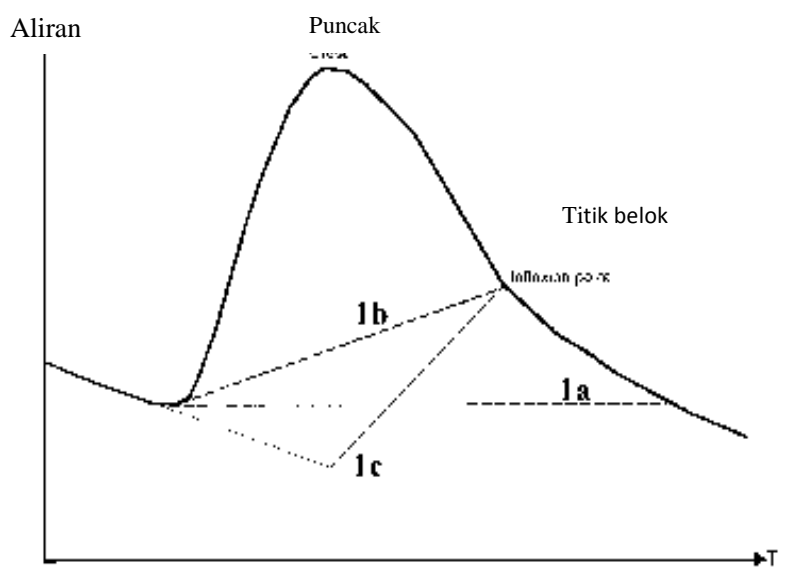

Gambar 1. Metode grafis untuk pemisahan aliran dasar (1a) konstanta discharge method, (1b) konstanta slope method dan (1c) concave method (Nathan dan McMahon, 1990).

di mana: $\mathrm{Q}=$ debit streamflow $\left(\mathrm{m}^{3} / \mathrm{det}\right), \mathrm{bt}=\mathrm{debit}$ aliran dasar $\left(\mathrm{m}^{3} / \mathrm{det}\right), \mathrm{q}=$ debit direct runoff $\left(\mathrm{m}^{3} / \mathrm{det}\right)$, $\alpha=$ parameter filter. Tiga metode pemisahan secara grafis disajikan pada Gambar 1.

Persamaan (1) dikoreksi atas data limpasan dan aliran dasar yang konstan pada saat limpasan langsung (direct runoff) berhenti, menjadi persamaan sebagai berikut:

$b_{t}=\frac{(3 \alpha-1)}{3-\alpha} x b_{t-1}+\frac{1-\alpha}{3-\alpha} x\left(Q_{t}-Q_{t-1}\right)$

Nilai $\alpha$ yang terbaik untuk penghitungan debit aliran dasar dari hidrograf aliran adalah 0,925 , dan polanya mengikuti trend hidrograf total runoff (Bloomfied dan Griffiths, 2009).

\section{HASIL DAN PEMBAHASAN}

Hasil pemisahan aliran dasar DAS Keduang memperoleh persamaan rating curve $\mathrm{Q}=7,85(\mathrm{H}-$ $0,275)^{0,382}$ dengan koefisien determinasi $\mathrm{R}^{2}=0,805$. Nilai ini berarti bahwa debit observasi dapat dijelaskan dengan debit prediksi sebesar 80,48\% seperti yang disajikan pada Gambar 2 .

Hasil analisis hidrograf resesi DAS Keduang yang disajikan pada Lampiran 1 menunjukkan bahwa hidrograf resesi tanggal 25 - 26 April 2008 (Anonim, 2008) mulai terjadi resesi yang ditandai dengan titik infleksi pada jam ke-18 dengan koefisien resesi (Krb) sebesar 0,990 dan volume baseflow rata-rata $5,703 \mathrm{~m}^{3} /$ detik. Hidrograf resesi tanggal $6-7$ Juli 2008 titik infleksi mulai terjadi pada jam ke-17 dengan koefisien resesi baseflow sebesar 0,994, baseflow rata-rata $5,009 \mathrm{~m}^{3} /$ detik, dan hidrograf resesi tanggal 23 - 24 Februari 2008 mulai terjadi resesi pada jam ke-32 dengan koefisien resesi sebesar 0,986, dan dan baseflow rata-rata 4,791 $\mathrm{m}^{3} /$ detik. Ketiga kurva resesi baseflow berdasarkan nilai koefisien resesi membentuk kurva resesi landau sebesar 98-99\%. 


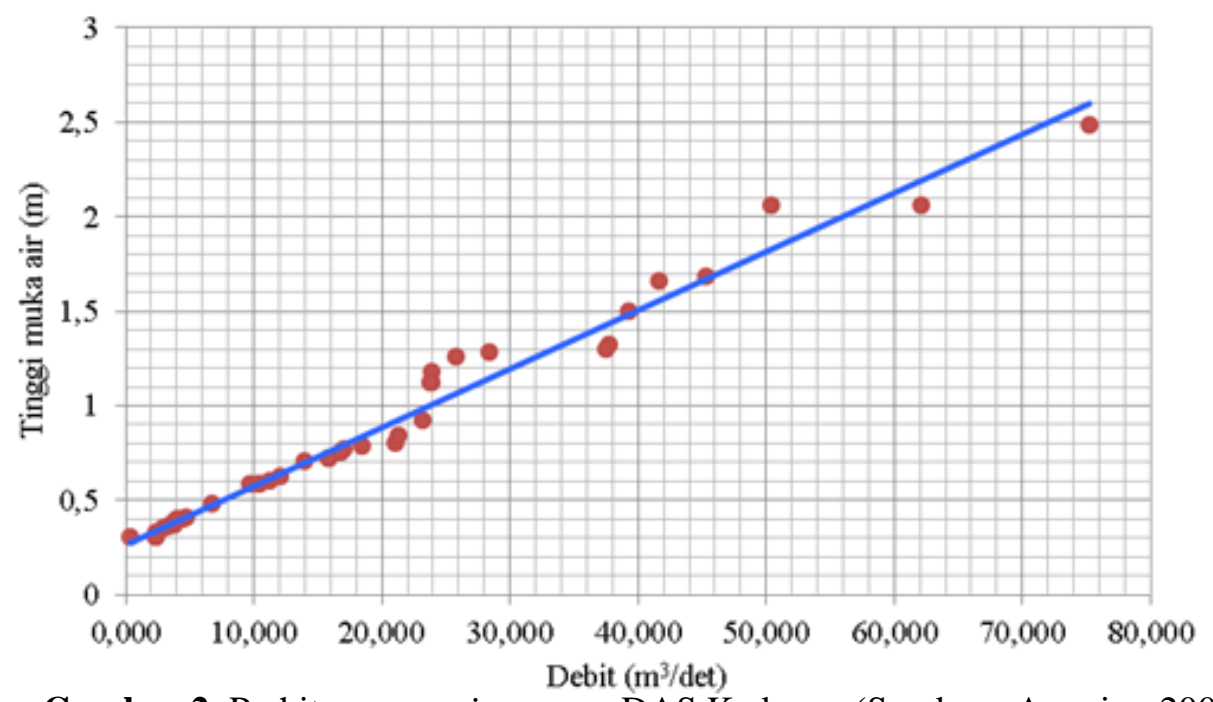

Gambar 2. Perhitungan rating curve DAS Keduang (Sumber : Anonim, 2008)

Berdasarkan hasil analisis koefisien resesi, kemudian dilakukan perhitungan hubungan debit dan baseflow disajikan pada Lampiran 2. Volume baseflow menunjukkan bahwa baseflow di DAS Keduang memiliki kapasitas simpanan yang baik, yakni memiliki kemampuan menyimpan dan meloloskan aliran ke sungai di musim kemarau. Namun perubahan lingkungan dikhawatirkan bisa mempengaruhi kebelanjutan aliran dasar dalam jangka panjang, karena baseflow merupakan fungsi dari sejumlah variabel fisik yang meliputi faktor topografi, iklim, geologi, litologi, dan aktivitas penggunaan lahan oleh manusia (Tallaksen, 1994).

\section{Hubungan geomorfologi (bentuklahan) dan aliran dasar}

Karakteristik hidrologi suatu daerah sangat dipengaruhi oleh geomorfologi terutama bentuklahan, dalam kaitannya dengan responnya terhadap aliran dasar sungai (Szilagyi dkk., 2007). Geomorfologi DAS Keduang terdiri atas bentuklahan kerucut vulkan $\left(17,001 \mathrm{~km}^{2}\right)$, lereng atas gunungapi $\left(35,004 \mathrm{~km}^{2}\right)$, lereng tengah gunungapi $\left(141,809 \mathrm{~km}^{2}\right)$, lereng bawah gunungapi $(106,16$ $\left.\mathrm{km}^{2}\right)$, escarpment $\left(32,216 \mathrm{~km}^{2}\right)$, lereng bawah gunungapi $\left(106,161 \mathrm{~km}^{2}\right)$, lereng perbukitan struktural $\left(47,038 \mathrm{~km}^{2}\right)$, perbukitan struktural $(6,349$ $\left.\mathrm{km}^{2}\right)$, dan lereng bawah $\left(1,721 \mathrm{~km}^{2}\right)$ disajikan pada Lampiran 3.

\section{Variasi penggunaan lahan pada beberapa tipe bentuklahan}

Peningkatan aliran sungai dan aliran dasar pada skala DAS merupakan pengaruh secara langsung maupun tidak langsung dari perubahan penggunaan lahan (Longobardi dan Villani, 2008). Variasi penggunaan lahan pada beberapa tipe bentuklahan di DAS Keduang menggambarkan kecenderungan yang beragam dalam responnya terhadap resesi aliran dasar (Zhang dan Schilling, 2005) disajikan pada Tabel 2.

Variasi penggunaan lahan hutan tetap menjadi hutan $(15,23 \%)$, hutan menjadi lahan pertanian $(15,55 \%)$, hutan menjadi pemukiman $(23,56 \%)$, lahan pertanian tetap lahan pertanian $(14,99 \%)$, lahan pertanian menjadi hutan $(10,33 \%)$, lahan pertanian menjadi pemukiman $(7,98 \%)$ dan pemukiman tetap menjadi pemukiman $(12,42 \%)$. Sementara variasi penggunaan lahan tertinggi terdapat pada beberapa tipe bentuklahan yakni lereng tengah gunungapi $(36,66 \%)$, lereng bawah gunungapi $(27,41 \%)$, lereng perbukitan struktural $(11,89 \%)$, lereng atas gunungapi $(9,05 \%)$, escarpment $(8,27 \%)$, kerucut vulkan $(4,42 \%)$, perbukitan struktural $(1,65 \%)$ dan lereng bawah $(0,65 \%)$.

Analisis statitika variasi penggunaan lahan pada berbagai tipe bentuklahan dan kaitannya dengan resesi aliran dasar

Koefisien determinasi adjusted $R^{2}$ yang diperoleh sebesar $(0,581)$, yang berarti terdapat korelasi cukup kuat antara variabel bebas dapat dijelaskan oleh variabel terikat sebesar $(58,1 \%)$. Selain itu 41,9\% dipengaruhi oleh faktor lain di luar variasi penggunaan lahan pada tipe bentuklahan seperti disajikan pada Tabel 3.

Hasil analisis statistik secara parsial pada Tabel 4 menunjukkan bahwa sebagian besar variasi penggunaan lahan pada unit bentuklahan berpengaruh signifikan terhadap resesi baseflow dengan nilai thitung $>\mathrm{t}$-Tabel $(1,969)$, pada signifikansi $<\alpha 0,05$ meliputi bentuklahan lereng atas gunungapi, lereng tengah gunungapi, lereng perbukitan struktural, perbukitan struktural dan escarpment; sementara variasi penggunaan lahan pada tipe bentuklahan kerucut vulkan, lereng bawah gunungapi, dan lereng bawah tidak berpengaruh signifikan terhadap aliran dasar sungai, dengan nilai t-hitung $<\mathrm{t}$-tabel pada signifikan yang $>\alpha 0,05$. 
Hasil analisis statistik secara simultan (uji ANOVA) data yang disajikan pada Tabel 5 menunjukkan bahwa variasi penggunaan lahan pada berbagai tipe bentuklahan berpengaruh signifikan terhadap aliran dasar sungai dengan hasil uji Fhitung $(49,967)>$ F-tabel $(1,972)$ pada signifikansi $(0,000)<\alpha 0,05$.

Model persamaan regresi ganda hubungan variasi penggunaan lahan pada berbagai tipe bentuklahan DAS Keduang dan karakteristik resesi baseflow adalah sebagai berikut :
$\mathrm{Y}=0,279+0,009 \mathrm{X}_{2}+0,001 \mathrm{X}_{3}+0,006 \mathrm{X}_{6}+0,303 \mathrm{X}_{7}$ $+0,006 X_{8}$

Model persamaan regresi tersebut mengandung pengertian bahwa jika variasi penggunaan lahan pada beberapa tipe bentuklahan meningkat sebesar $1 \%$, maka aliran dasar sungai akan meningkat. Hal ini terlihat antara lain untuk tipe bentuklahan lereng atas gunungapi meningkat sebesar $0,002 \%$, lereng tengah gunungapi 009 , lereng perbukitan struktural $0,006 \%$, perbukitan struktural $0,019 \%$, dan escarpment $0,014 \%$. Hasil analisis regresi ganda

Tabel 2. Variasi penggunaan lahan pada berbagai tipe bentuklahan (dalam \%).

\begin{tabular}{|c|c|c|c|c|c|c|c|c|c|}
\hline \multirow[t]{2}{*}{ Variasi PL } & \multicolumn{8}{|c|}{ Unit bentuklahan } & \multirow[t]{2}{*}{ Total } \\
\hline & KV & LAG & LTG & LBG & LB & LPS & PS & Esc & \\
\hline $\mathrm{H}-\mathrm{H}$ & 0,89 & 1,33 & 4,36 & 0,66 & 0,10 & 4,99 & 0,10 & 2,80 & 15,23 \\
\hline $\mathrm{H}-\mathrm{LP}$ & 1,88 & 0,03 & 6,30 & 6,62 & 0,06 & 0,49 & 0,02 & 0,14 & 15,55 \\
\hline $\mathrm{H}-\mathrm{PMK}$ & 0,15 & 1,24 & 13,10 & 8,45 & 0,18 & 0,03 & 0,13 & 0,26 & 23,56 \\
\hline LP - LP & 0,29 & 2,25 & 4,08 & 4,73 & 0,05 & 1,54 & 0,23 & 1,78 & 14,93 \\
\hline $\mathrm{LP}-\mathrm{H}$ & 1,08 & 1,87 & 2,53 & 0,66 & 0,10 & 2,56 & 0,77 & 0,75 & 10,33 \\
\hline LP - PMK & 0,03 & 0,01 & 3,80 & 2,87 & 0,13 & 0,16 & 0,29 & 0,70 & 7,98 \\
\hline PMK-PMK & 0,10 & 2,34 & 2,49 & 3,41 & 0,02 & 2,11 & 0,11 & 1,83 & 12,42 \\
\hline Total & $\mathbf{4 , 4 2}$ & 9,05 & 36,66 & 27,41 & $\mathbf{0 , 6 5}$ & 11,89 & 1,65 & 8,27 & 100 \\
\hline
\end{tabular}

Keterangan : KV=kerucut vulkan, LAG = lereng atas gunungapi, $\mathrm{LTG}=$ lereng tengah gunungapi, $\mathrm{LBG}=$ lereng bawah gunungapi, LB = lereng bawah, LPS= lereng perbukitan struktural, PS=perbukitan struktural, Esc= escarpment. Sumber : Data Primer, 2010.

Tabel 3. Variasi penggunaan lahan pada berbagai tipe bentuklahan terhadap resesi baseflow.

\begin{tabular}{cccccc}
\hline Model & $\mathrm{R}$ & $\mathrm{R}^{2}$ & Adjusted $\mathrm{R}^{2}$ & $\mathrm{SD}$ & Durbin-Watson \\
\hline 1 & $0,770^{\mathrm{a}}$ & 0,593 & 0,581 & 1,261 & 0,953 \\
\hline a. Variabel bebas : variasi penggunaan lahan pada unit bentuklahan escarpment, lereng tengah gunungapi, \\
perbukitan struktural, lereng bawah gunungapi, lereng atas gunungapi, lereng bawah, lereng perbukitan \\
struktural, kerucut vulkan . \\
b. Variabel terikat : baseflow ( $\left.\mathrm{m}^{3} / \mathrm{det}\right)$.
\end{tabular}

Tabel 4. Analisis parsial variasi penggunaan lahan pada berbagai tipe bentuklahan terhadap koefisien resesi baseflow.

\begin{tabular}{|c|c|c|c|c|c|}
\hline \multirow[t]{2}{*}{ Model } & \multicolumn{2}{|c|}{ Koefisien tak terstandarisasi } & \multirow{2}{*}{$\begin{array}{c}\begin{array}{c}\text { Koefisien } \\
\text { terstandarisasi }\end{array} \\
\text { Beta }\end{array}$} & \multirow[t]{2}{*}{$\mathrm{t}$} & \multirow[t]{2}{*}{ Sig. } \\
\hline & B & SD & & & \\
\hline Konstanta & 0,28 & 0,08 & & 3.52 & 0,00 \\
\hline Kerucut vulkan & 0,00 & 0,00 & 0,05 & 0,81 & 0,42 \\
\hline Lereng atas gunungapi & 0,01 & 0,00 & 0,31 & 7,09 & 0,00 \\
\hline Lereng tengah gunungapi & 0,00 & 0,00 & 0,11 & 2,39 & 0,02 \\
\hline Lereng bawah gunungapi & 0,00 & 0,00 & 0,03 & 0,80 & 0,42 \\
\hline Lereng bawah & 0,04 & 0,02 & 0,10 & 1,78 & 0,08 \\
\hline Lereng perbukitan struktural & 0,01 & 0,00 & 0,22 & 4,94 & 0,00 \\
\hline Perbukitan struktural & 0,02 & 0,01 & 0,18 & 4,13 & 0,00 \\
\hline Escarpment & 0,01 & 0,00 & 0,37 & 8,16 & 0,00 \\
\hline
\end{tabular}

a. Variabel terikat : baseflow $\left(\mathrm{m}^{3} / \mathrm{det}\right)$.

Tabel 5. Analisis ANOVA variasi penggunaan lahan pada berbagai tipe bentuklahan terhadap koefisien resesi baseflow.

\begin{tabular}{lrrrrr}
\hline \multicolumn{1}{c}{ Model } & Jumlah kuadrat & df & Mean $^{2}$ & F & Sig. \\
\hline Regresi & 635,625 & 8 & 79,453 & 49,967 & $0,000^{\mathrm{b}}$ \\
Residual & 435,694 & 274 & 1,590 & & \\
Total & 1071,320 & 282 & & & \\
\hline
\end{tabular}

a. Variabel terikat: baseflow $\left(\mathrm{m}^{3} / \mathrm{det}\right)$.

b. Variabel bebas: variasi penggunaan lahan pada bentuklahan escarpment, lereng tengah gunungapi, perbukitan struktural, lereng bawah gunungapi, lereng atas gunungapi, lereng bawah, lereng perbukitan struktural, kerucut vulkan. 
variasi penggunaan lahan pada berbagai tipe bentuklahan secara spasial disajikan pada Lampiran 4. Hasil analisis secara analisis parsial dan simultan menunjukkan perubahan yang signifikan untuk variasi penggunaan lahan pada berbagai tipe bentuklahan terhadap aliran dasar sungai

\section{KESIMPULAN}

Karakteristik resesi aliran dasar di DAS Keduang secara grafis digambarkan melalui bentuk kurva resesi yang landai dengan nilai koefisien resesi 0,99 dan volume baseflow rata-rata yang cukup besar. Variasi penggunaan lahan pada berbagai tipe bentuklahan menunjukkan bahwa sebagian besar berpengaruh signifikan terhadap aliran dasar sungai meliputi lereng atas gunungapi, lereng tengah gunungapi, lereng perbukitan struktural, perbukitan struktural dan escarpment. Untuk variasi penggunaan lahan pada tipe bentuklahan kerucut vulkan, lereng bawah gunungapi, dan lereng bawah tidak berpengaruh signifikan.

Karakteristik aliran dasar sungai merupakan hasil interdepedensi dan interrelasi antara parameter geomorfologi (bentuklahan), litologi (batuan), iklim, morfometri DAS, dan penggunaan lahan. Oleh karena itu pengelolaan aliran dasar sungai skala DAS membutuhkan sinergitas semua aspek lingkungan secara holistik dan berkesinambungan.

\section{UCAPAN TERIMAKASIH}

Pada kesempatan ini penulis mengucapkan banyak terima kasih kepada pimpinan dan staf Balai Penelitian dan Teknologi Pengelolaan Daerah Aliran Sungai (BPTPDAS) Surakarta, Kementerian Lingkungan Hidup dan Kehutanan atas kesempatan yang diberikan untuk mengumpulkan data sekunder debit, peta penggunaan lahan dan citra satelit yang terkait dengan penyelesaian tulisan ini.

\section{DAFTAR PUSTAKA}

Anonim, 2008. Analisis Data Debit dengan Sumber Data, Balai Penelitian dan Teknologi Pengelolaan Daerah Aliran Sungai (BPTPDAS) Surakarta, Surakarta.

Anonim, 2010. Analisis Citra Landsat untuk Morfometri DAS Keduang Kabupaten Wonogiri Provinsi Jawa Tengah, Semarang.

Asdak, C., 2002. Hutan dan Perilaku Aliran Air : Klasifikasi Keberadaan Hutan dan Pengaruhnya terhadap Banjir dan Kekurangan Air. Jurnal Manusia dan Lingkungan, 9(1):4049.
Bloomfield, J.P., dan Griffiths, D.J., 2009. Examining Geological Controls on Baseflow Index (BFI) Using Regresi Analysis: An Illustration from the Thames Basin, UK. Journal of Hydrology, 373:164-176.

Eckhardt, K., 2005. How to Construct Recursive Digital Filters for Baseflow Separation? Hydrological Processes, 19:507-515.

Longobardi, A. dan Villani P., 2008. Baseflow Index Regionalization Analysis in a Mediterranean Area and Data Scarcity Context : Role of The Catchment Permesbility Index. Journal of Hydrology, 355:63-75.

Nathan, R.J., dan McMahon, T.A., 1990. Evaluation of Automated Techniques for Base Flow and Recession Analysis. Water Resources Research, 26(7):1465-1473.

Pontius, R.G. dan Schneider, L.C., 2001. Land-cover change model validation by an ROC method for the Ipswich watershed, Massachusetts, USA. Agriculture, Ecosystem and Environment. 85:239-248.

Seyhan, E. 1990. Dasar-Dasar Hidrologi. Gadjah Mada University Press. Yogyakarta.

Szilagyi, J., Gribovszki, Z., dan Kalicz, P., 2007. Estimation of Catchment-Scale Evapotranspiration from Baseflow Recession Data: Numerical Model and Practical Application Results. Journal of Hydrology 336: 206-217.

Tallaksen, L.M., 1994. A Review of Baseflow Recession Analysis. Journal of Hydrology, 165:349-370.

Turner, M.G., Gardner, R.H., dan O’Neill, R.V., 2001. Landscape Ecology in Theory and Practice Pattern and Process. Springer-Verlag, New York, 401.

Verburg, P.H., van Eck, J.R., de Hijs, T.C., Dijst, M.J., dan Schot, P., 2004. Determination of Land Use Change Patterns in the Netherlands. Journal of Environmental Planning, 31:125150.

Wittenberg, H., dan Sivapalan, M., 1999. Watershed Groundwater Balance Estimation using Streamflow Recession Analysis and Baseflow Separation. Journal of Hidrology, 219:20-33.

Yu-Pin, L., Nien-Ming, H., Pei-Jung, W., Chen-Fa, W., dan Verbur, P.H., 2007. Impacts of Land Use Change Scenarios on Hydrology and Land Use Patterns in the Wu-Tu Watershed in Northern Taiwan. Landscape and Urban Planning, 80:111-126.

Zhang, Y.K., and Schilling, K.E., 2005. I Streamflow and Baseflow in Mississippi River Since the 1940 s: Effect of Land Use Change. Journal of Hydrology, 324:412-422. 